\title{
Exploring the Ruthenium-Ligands Bond and Their Relative Properties at Different Computational Methods
}

\author{
Adebayo A. Adeniyi and Peter A. Ajibade \\ Department of Chemistry, University of Fort Hare, Private Bag Box X1314, Alice 5700, South Africa \\ Correspondence should be addressed to Peter A. Ajibade; pajibade@ufh.ac.za
}

Received 21 September 2015; Revised 17 November 2015; Accepted 25 November 2015

Academic Editor: Maria F. Carvalho

Copyright (C) 2016 A. A. Adeniyi and P. A. Ajibade. This is an open access article distributed under the Creative Commons Attribution License, which permits unrestricted use, distribution, and reproduction in any medium, provided the original work is properly cited.

\begin{abstract}
We report some experimental bond distances and computational models of six ruthenium bonds obtained from DFT to higher computational methods like MP2 and CCSD. The bonds distances, geometrical RMSD, and the thermodynamic properties of the models from different computational methods are similar. It is observed that optimization of molecules of many light atoms with different functional methods results in significant geometrical variation in the values and order of the computed properties. The values of the hyperpolarizabilities, HOMO, LUMO, and isotropic and anisotropic shielding are found to depend greatly on the type of the functional used and the geometrical variation rather than on the nature of basis set used. However, all the methods rated modelled $\mathrm{Ru}-\mathrm{S}, \mathrm{Ru}-\mathrm{Cl}$, and $\mathrm{Ru}-\mathrm{O}$ bonds as having the highest hyperpolarizabilities values. The infrared spectra data obtained from the different computational methods are significantly different from each other except for MP2 and CCSD which are found to be very similar.
\end{abstract}

\section{Introduction}

Ruthenium complexes have received significant consideration as conductive, optical, anticancer, and antibiotic applications [1-16]. Besides great number of ruthenium complexes, there are many of the ruthenium-ligand bonds which are found relevant to their biological activities. The covalent bonding between $\mathrm{Ru}$ and N7 (guanine) is considered the predominant mode of action with DNA for Ru antitumor compounds [17-19]. It was also assumed that metals can form chelates with N7 and O6 atoms of guanine [20]. The formation of a hydrolyzed $\mathrm{Ru}-\mathrm{O}$ bond is very significant for the activation of ruthenium complexes for biological activities $[19,21]$. The rate of hydrolysis has significant effect on the anticancer activities [22-24]. Ruthenium has also been reported to bind to $S$ of Cys. residue of Cathepsin B [25-27]. Mostly for Ru anticancer activities, bonding between $\mathrm{Ru}$ and N7 (guanine) is considered to be the predominant mode of action with DNA [17]. However, it is also possible that binding to guanine N7 atoms is less important than other types of interaction like interaction with phosphate groups, hydrogen bonds, and so forth [28].
The computational approach is very significant for the optimization of the complexes and design of novel complexes for various applications, studying their electronic, conductive, and spectroscopic properties in relation to their stability. However, it is computationally expensive to compute the properties of ruthenium complexes using higher basis set like aug-cc-pVTZ and high perturbation method like MP2. It is therefore highly important to optimize the computational methods which are affordable for the ruthenium complexes. In this paper, we have presented different models of ruthenium complexes which are different by the type of the ruthenium-ligand ( $\mathrm{Ru}-\mathrm{L})$ bonds. The types of the $\mathrm{Ru}-$ $\mathrm{L}$ bond of interest to us are $\mathrm{Ru}-\mathrm{C}, \mathrm{Ru}-\mathrm{N}, \mathrm{Ru}-\mathrm{O}, \mathrm{Ru}-\mathrm{P}, \mathrm{Ru}-$ $\mathrm{S}, \mathrm{Ru}-\mathrm{Cl}$, and $\mathrm{Ru}-\mathrm{H}$ which are common to many of the synthesised ruthenium complexes for various applications as shown in Table 1. The effects of the functional methods and the level of basis sets on the Ru-L bond length and their relative properties are presented with the intention to find cheaper and approachable computational methods for ruthenium complexes. 
TABLE 1: The experimental bond distances for $\mathrm{Ru}-\mathrm{L}$ which are found to be common in different ruthenium complexes.

\begin{tabular}{|c|c|c|c|c|c|c|}
\hline $\mathrm{Ru}-\mathrm{C}$ & $\mathrm{Ru}-\mathrm{N}$ & $\mathrm{Ru}-\mathrm{O}$ & $\mathrm{Ru}-\mathrm{P}$ & $\mathrm{Ru}-\mathrm{S}$ & $\mathrm{Ru}-\mathrm{Cl}$ & $\mathrm{Ru}-\mathrm{H}$ \\
\hline $1.827[44]$ & 1.940 to 2.137 [45] & 2.00 to $2.01[46]$ & 2.2587 to 2.3141 [47] & 2.246 to $2.266[48]$ & 2.2971 to $2.3680[49]$ & $1.494[44]$ \\
\hline 1.845 to $2.220[50]$ & 2.00 to 2.053 [46] & 2.0514 to 2.091 [47] & $2.277[50]$ & 2.2777 to $2.3050[51]$ & 2.327 to $3.366[51]$ & $\begin{array}{c}1.57 \text { to } 1.59 \\
{[52]}\end{array}$ \\
\hline 1.865 to 2.035 [53] & 2.0190 to 2.0914 [49] & 2.058 to $2.074[54]$ & 2.279 to 2.298 [54] & 2.3436 to 2.3737 [55] & 2.359 to 2.388 [45] & \\
\hline $2.083[1]$ & 2.024 to $2.114[51]$ & $2.0656[51]$ & 2.2812 to $2.4188[52]$ & & 2.3726 to 2.3885 [53] & \\
\hline 2.109 to 2.287 [55] & 2.025 to $2.047[46]$ & 2.066 to 2.092 [44] & 2.31 to 2.389 [47] & & 2.407 to 2.418 [37] & \\
\hline 2.116 to 2.1777 [43] & 2.066 to 2.196 [56] & 2.076 to 2.109 [49] & 2.3165 to 2.3679 [57] & & 2.407 to $2.4511[46]$ & \\
\hline \multirow[t]{4}{*}{2.199 to $2.281[58]$} & 2.0703 to 2.183 [53] & 2.0783 to 2.118 [53] & $2.336[46]$ & & 2.411 to $2.434[54]$ & \\
\hline & $2.0792[58]$ & 2.18 to $2.23[59]$ & 2.363 to $2.378[44]$ & & 2.431 to 2.4823 [47] & \\
\hline & 2.107 to $2.122[60]$ & & $2.412[56]$ & & 2.434 to $2.4567[51]$ & \\
\hline & 2.141 to $2.196[44]$ & & & & $2.4357[1]$ & \\
\hline
\end{tabular}

\section{Computational Method}

Six models of common ruthenium-ligand bonds which are $\mathrm{H}_{5} \mathrm{Ru}-\mathrm{CH}_{3}, \mathrm{H}_{5} \mathrm{Ru}-\mathrm{NH}_{2}, \mathrm{H}_{5} \mathrm{Ru}-\mathrm{OH}, \mathrm{H}_{5} \mathrm{Ru}-\mathrm{Cl}, \mathrm{H}_{5} \mathrm{Ru}-\mathrm{PH}_{3}$, and $\mathrm{H}_{5} \mathrm{Ru}-\mathrm{SH}_{3}$ were built to represent common types of bonds in ruthenium-ligand complexes and in rutheniumreceptor interactions. The models were optimized with DFT hybrid functional like PBE [29] and B3LYP [30] and other higher computational methods like MP2 and CCSD using mixed basis sets of SBKJC VDZ [31] for Ru atom and $6-31+G(d, p)$ for other atoms. Many of the properties are computed using DGDZVP for $\mathrm{Ru}$, while others were treated with $6-31+G(d, p)$. Also, for better simulation results, the models were treated with higher perturbation method, MP2, and at higher basis set, aug-cc-pVTZ, for all the atoms including ruthenium. In all the methods, all atoms besides the $\mathrm{Ru}$ atom are treated with $6-31+\mathrm{G}(\mathrm{d}, \mathrm{p})$ basis set except when basis sets aug-cc-pVTZ was applied on all atoms. Therefore, in the methods where different basis set is applied on $\mathrm{Ru}$ atom, the method will be reference based on the type of basis set applied on the Ru atom. All the computational methods, B3LYP/SBKJC-VDZ, PBE/SBKJC-VDZ, MP2/SBKJC-VDZ, CCSD/SBKJC-VDZ, B3LYP/DGDZVP, PBE/DGDZVP, MP2/DGDZVP, and CCSD/DGDZVP, and all other atoms beside $\mathrm{Ru}$ atom were treated with $6-31+\mathrm{G}(\mathrm{d}, \mathrm{p})$ while in the MP2/aug-cc-pVTZ method, all the atoms were treated with the same basis set. All the computation was done using Gaussian 09 [32] and external basis set aug-cc-pVTZ for $\mathrm{Ru}$ atom EMSL Basis Set Library $[33,34]$ and incorporated into the input file in a format that Gaussian 09 programs can read. The first hyperpolarizability tensors were calculated from the Gaussian output using $\left(b_{i j k}\right)=B_{\text {tot }}=\left(B_{x}{ }^{2}+B_{y}{ }^{2}+\right.$ $\left.\beta_{z}{ }^{2}\right)^{1 / 2}$, where $\beta_{x}=\left(\beta_{x x x}+\beta_{x y y}+\beta_{x z z}\right), \beta_{y}=\left(\beta_{y y y}+\beta_{y x x}+\right.$ $\left.\beta_{y z z}\right)$, and $\beta_{z}=\left(\beta_{z x x}+\beta_{z y y}+\beta_{z z z}\right)$ [35, 36]. The atomic units (a.u.) of $\beta$ in G09 were converted into electrostatic units (esu) $\left(1\right.$ a.u. $=8.6393 \times 10^{-33}$ esu). The IR spectra of the molecules were assigned through the method of potential energy distribution (PED) contributions as implemented in VEDA package [37] and explained in the literatures [38, 39].

\section{Results and Discussion}

Six models of ruthenium-ligand bonds ( $\mathrm{Ru}-\mathrm{C}, \mathrm{Ru}-\mathrm{N}, \mathrm{Ru}-\mathrm{O}$, $\mathrm{Ru}-\mathrm{Cl}, \mathrm{Ru}-\mathrm{P}$, and $\mathrm{Ru}-\mathrm{S}$ ) are modelled and were optimized using the functionals MP2, CCSD, PBE, and B3LYP. Many of their properties like their hyperpolarizabilities and isotropic and anisotropic shielding tensors are computed using the functionals with different basis sets like SBKJC-VDZ $\{\mathrm{Ru}\}$ 6$31+G(d, p), D G D Z V P\{R u\} 6-31+G(d, p)$, and aug-cc-pVTZ.

3.1. Bonds and the Thermodynamic Properties Dependent on Functional Methods. Different bond distances of rutheniumligands ( $\mathrm{Ru}-\mathrm{L})$ which are reported in the literatures from their crystal structures are shown in Table 1. From the crystal structures of ruthenium complexes, the range of the experimental bond length for Ru-C is 1.827 to 2.281 , that of $\mathrm{Ru}-\mathrm{N}$ is 1.940 to 2.196 , that of $\mathrm{Ru}-\mathrm{O}$ is 2.00 to 2.23 , that of $\mathrm{Ru}-\mathrm{Cl}$ is 2.2971 to 2.4357 , that of $\mathrm{Ru}-\mathrm{P}$ is 2.2587 to 2.412 , that of $\mathrm{Ru}-\mathrm{S}$ is 2.246 to 2.3737 , and that of $\mathrm{Ru}-\mathrm{H}$ is 1.494 to 1.59 (Table 1). The general features of the experimental Ru-L bond lengths are in the order of $\mathrm{Ru}-\mathrm{Cl}>\mathrm{Ru}-\mathrm{P}>\mathrm{Ru}-\mathrm{S}>\mathrm{Ru}-\mathrm{O}>$ $\mathrm{Ru}-\mathrm{N}>\mathrm{Ru}-\mathrm{C}>\mathrm{Ru}-\mathrm{H}$. The $\mathrm{Ru}-\mathrm{L}$ bond distances of the six models which are obtained from the optimized geometries at MP2, CCSD, PBE, and B3LYP level of theories are shown in Figure 1. The general features of the Ru-L bond lengths of the six models using different computational methods show a common order of Ru-P $>\mathrm{Ru}-\mathrm{S}>\mathrm{Ru}-\mathrm{Cl}>\mathrm{Ru}-\mathrm{C}>\mathrm{Ru}-\mathrm{O}>$ $\mathrm{Ru}-\mathrm{N}$. The observed similarity in the bond orders between the experimental and theoretical is that they both rated $\mathrm{Ru}$ $\mathrm{Cl}, \mathrm{Ru}-\mathrm{P}$, and $\mathrm{Ru}-\mathrm{S}$ higher than $\mathrm{Ru}-\mathrm{O}, \mathrm{Ru}-\mathrm{N}$, and $\mathrm{Ru}-\mathrm{C}$. The computed range of bond values for $\mathrm{Ru}-\mathrm{C}$ is 1.94 to 1.98 in the order of MP2 $<\mathrm{PBE}<\mathrm{B} 3 \mathrm{LYP}<\mathrm{CCSD}$, that of $\mathrm{Ru}-\mathrm{N}$ is 1.83 to 1.87 in the order of MP2 $<$ B3LYP $<$ CCSD $<$ PBE, that of Ru$\mathrm{O}$ is 1.85 to 1.87 in the order of MP2 $<\mathrm{CCSD}<\mathrm{B} 3 \mathrm{LYP}<\mathrm{PBE}$, that of $\mathrm{Ru}-\mathrm{Cl}$ is 2.17 to 2.21 in the order of MP2 $<\mathrm{CCSD}<$ B3LYP $<$ PBE, that of Ru-P is 2.39 to 2.45 in the order of $\mathrm{MP} 2<\mathrm{PBE}<\mathrm{B} 3 \mathrm{LYP}<\mathrm{CCSD}$, and that of Ru-S is 2.21 to 2.24 in the order of MP2 < PBE $<$ B3LYP $<$ CCSD. In both $\mathrm{Ru}-\mathrm{N}$ and $\mathrm{Ru}-\mathrm{Cl}$, the functional PBE overestimates the bonds 


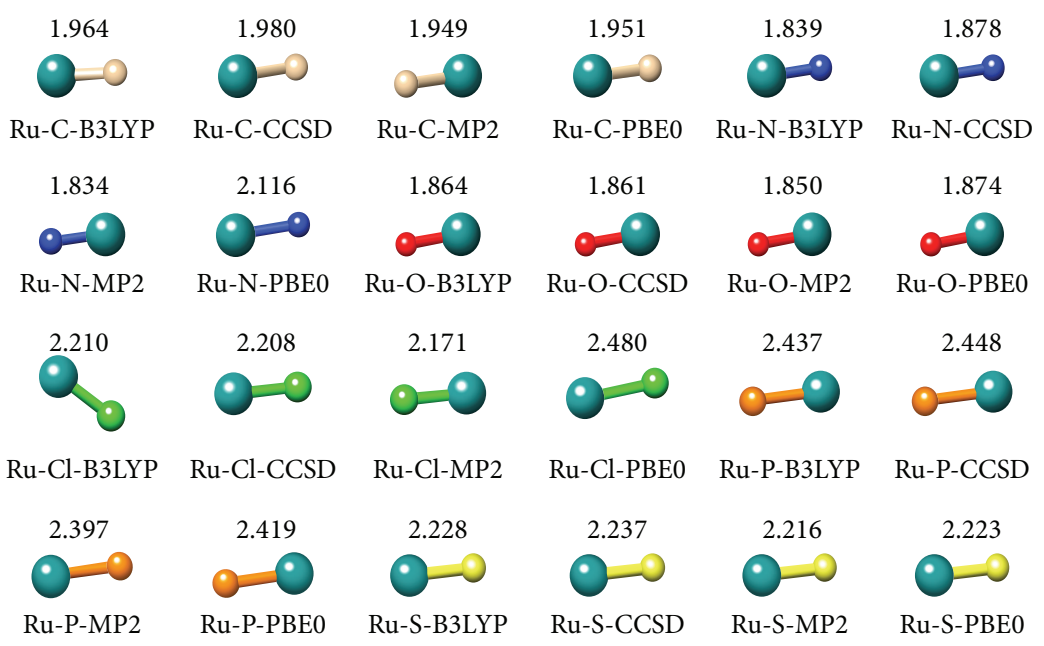

FIGURE 1: The bond distances of the six models of Ru-L bonds obtained from the optimized geometries at MP2, CCSD, PBE, and B3LYP using SBKJC VDZ basis set.

TABLE 2: The bond distances and thermodynamic properties using MP2/ECP method and the differences using other methods (energies in $\mathrm{KJ} / \mathrm{Mol}$ ).

\begin{tabular}{|c|c|c|c|c|c|c|c|c|}
\hline Method/bonds & Distance & Energy & Zero energy & Thermal energy & Enthalpy & Gibbs-free & CV KJ/Mol-K & $S \mathrm{KJ} / \mathrm{Mol}-\mathrm{K}$ \\
\hline Ru-C-MP2-ECP & 1.9485 & $-3.5376 E+05$ & $-3.5457 E+05$ & $-3.5455 E+05$ & $-3.5455 E+05$ & $-3.5464 E+05$ & 0.0782 & 0.2901 \\
\hline Ru-N-MP2-ECP & 1.8342 & $-3.5376 E+05$ & $-3.5457 E+05$ & $-3.5455 E+05$ & $-3.5455 E+05$ & $-3.5464 E+05$ & 0.0782 & 0.2901 \\
\hline Ru-O-MP2-ECP & 1.8501 & $-3.9584 E+05$ & $-3.9681 E+05$ & $-3.9679 E+05$ & $-3.9679 E+05$ & $-3.9688 E+05$ & 0.0769 & 0.2940 \\
\hline Ru-Cl-MP2-ECP & 2.1711 & $-4.4927 E+05$ & $-4.5022 E+05$ & $-4.5021 E+05$ & $-4.5021 E+05$ & $-4.5029 E+05$ & 0.0736 & 0.2927 \\
\hline Ru-P-MP2-ECP & 2.3969 & $-1.1493 E+06$ & $-1.1499 E+06$ & $-1.1499 E+06$ & $-1.1499 E+06$ & $-1.1500 E+06$ & 0.0973 & 0.3293 \\
\hline u-S-MP2-ECP & 2157 & $-1.2964 E+06$ & $-1.2973 E+06$ & $-1.2972 E+06$ & -1.297 & -1.29 & 855 & 0.3188 \\
\hline \multicolumn{9}{|c|}{ Difference of the other methods from MP2/SBKJC VDZ } \\
\hline Ru-C-PBE-ECP & 0.0024 & $-2.9890 E+03$ & $-1.9950 E+03$ & $-1.9946 E+03$ & $-1.9946 E+03$ & $-1.9955 E+03$ & 0.0017 & 0.0032 \\
\hline Ru-N-PBE-ECP & 0.0120 & $-2.9890 E+03$ & $0 E+03$ & $6 E+03$ & $-1.9946 E+03$ & $5 E+03$ & & \\
\hline Ru-O-PBE-ECP & 0.0243 & $-3.1318 E+03$ & $-1.9966 E+03$ & $-1.9970 E+03$ & $-1.9970 E+03$ & $-1.9959 E+03$ & -0.0011 & 037 \\
\hline Ru-Cl-PBE-ECP & 0.3088 & $-3.2116 E+03$ & $-2.1228 E+03$ & $-2.1223 E+03$ & $-2.1223 E+03$ & $-2.1231 E+03$ & & 0.0027 \\
\hline Ru-P-PBE-ECP & 0.0219 & $-3.5356 E+03$ & $-2.7378 E+03$ & $-2.7373 E+03$ & $-2.7373 E+03$ & $-2.7386 E+03$ & & \\
\hline Ru-S-PBE-ECP & 0.0074 & $-3.7839 E+03$ & $-2.8207 E+03$ & $-2.8208 E+03$ & $-2.8208 E+03$ & $-2.8202 E+03$ & 0.0007 & 019 \\
\hline Ru-C-B3LYP-ECP & 0.0159 & $-3.1831 E+03$ & $-2.1836 E+03$ & $-2.1828 E+03$ & $-2.1828 E+03$ & $-2.1844 E+03$ & 0.0039 & 0.0055 \\
\hline Ru-N-B3LYP-ECP & 0.0047 & $-4.5407 E+04$ & $-4.4429 E+04$ & $-4.4429 E+04$ & $-4.4429 E+04$ & $-4.4429 E+04$ & -0.0012 & 0.0010 \\
\hline Ru-O-B3LYP-ECP & 0.0144 & $-3.3288 E+03$ & $-2.1890 E+03$ & $-2.1893 E+03$ & $-2.1893 E+03$ & $-2.1884 E+03$ & 0.0000 & -0.0028 \\
\hline Ru-Cl-B3LYP-ECP & 0.0392 & $-3.4479 E+03$ & $-2.3536 E+03$ & $-2.3531 E+03$ & $-2.3531 E+03$ & $-2.3540 E+03$ & 0.0022 & 0.0031 \\
\hline Ru-P-B3LYP-ECP & 0.0398 & $-4.0797 E+03$ & $-3.2774 E+03$ & $-3.2764 E+03$ & $-3.2764 E+03$ & $-3.2788 E+03$ & 0.0031 & 0.0081 \\
\hline Ru-S-B3LYP-ECP & 0.0125 & $-4.3126 E+03$ & $-3.3423 E+03$ & $-3.3431 E+03$ & $-3.3431 E+03$ & $-3.3414 E+03$ & -0.0029 & -0.0057 \\
\hline Ru-C-CCSD-ECP & 0.0316 & $-2.1515 E+01$ & $-7.1138 E+01$ & $-6.9570 E+01$ & $-6.9570 E+01$ & $-7.2697 E+01$ & 0.0075 & 0.0105 \\
\hline Ru-N-CCSD-ECP & 0.0436 & $-4.2095 E+04$ & $-4.2295 E+04$ & $-4.2294 E+04$ & $-4.2294 E+04$ & $-4.2295 E+04$ & 0.0024 & 0.0047 \\
\hline Ru-O-CCSD-ECP & 0.0109 & $-1.6767 E+01$ & $-5.4986 E+01$ & $-5.4600 E+01$ & $-5.4600 E+01$ & $-5.4878 E+01$ & 0.0037 & 0.0009 \\
\hline Ru-Cl-CCSD-ECP & 0.0368 & $-2.4604 E+01$ & $-6.5007 E+01$ & $-6.4330 E+01$ & $-6.4330 E+01$ & $-6.5559 E+01$ & 0.0037 & 0.0041 \\
\hline Ru-P-CCSD-ECP & 0.0512 & $-1.4740 E+00$ & $-1.2560 E+02$ & $-1.2351 E+02$ & $-1.2351 E+02$ & $-1.2915 E+02$ & 0.0066 & 0.0189 \\
\hline Ru-S-CCSD-ECP & 0.0211 & $-3.7429 E+01$ & $-9.8966 E+01$ & $-9.9562 E+01$ & $-9.9562 E+01$ & $-9.8230 E+01$ & -0.0017 & -0.0045 \\
\hline
\end{tabular}

above other functional methods. $\mathrm{Ru}-\mathrm{C}$ bond values of our model are within the common experimental bond values for $\mathrm{Ru}-\mathrm{C}$, while the values obtained for other modelled bonds are little below the common experimental values. If the bond values obtained using the MP2 are compared to the analytical values, the differences in the values of other computational methods from MP2 are calculated using simple expression $X_{\text {other }}-X_{\mathrm{MP} 2}$ and are presented in Table 2. The differences in bond values obtained using PBE compared to the analytical values from MP2 are smaller in magnitude compared to other methods (Table 2) but the order of the bond distances in the model was not perfectly reproduced as in B3LYP and CCSD 

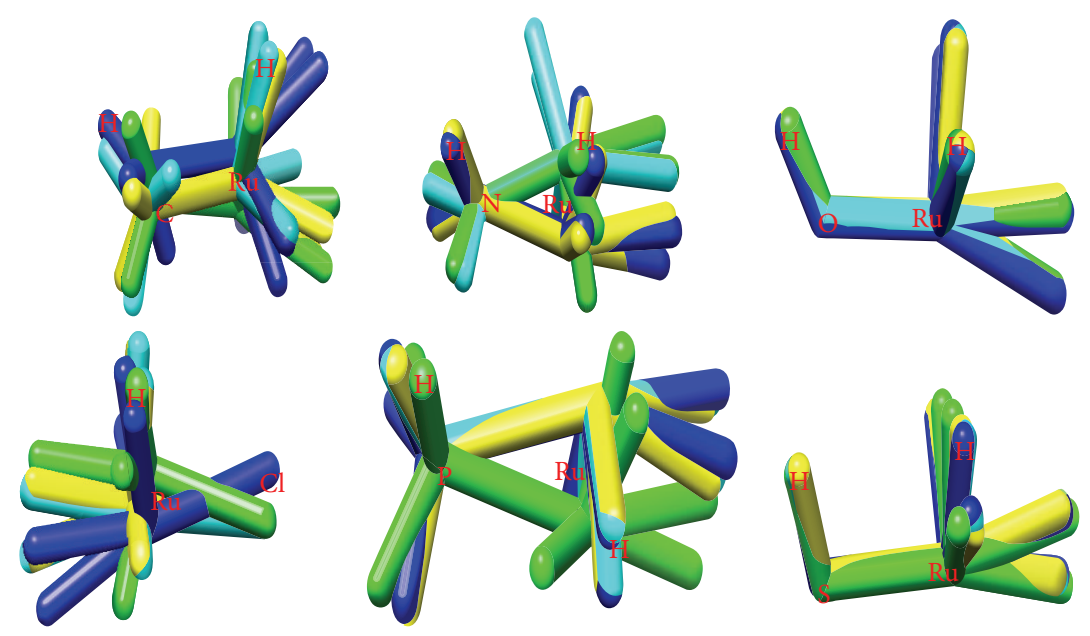

FIGURE 2: The superposition of different model of Ru-L bonds obtained using MP2 (green), CCSD (blue), PBE (yellow), and B3LYP (cyan) to determine the RMSD of the whole geometries after the optimization of their respective geometries.

TABLE 3: The correlation of the values of energy and thermodynamics properties at MP2/SBKJC VDZ with other computational methods.

\begin{tabular}{lccc}
\hline MP2-ECP & PBE & B3LYP & CCSD \\
\hline Ru-L-dist & 1.00 & 1.00 & 1.00 \\
Energy & 1.00 & 1.00 & 1.00 \\
Zero energy & 1.00 & 1.00 & 1.00 \\
Thermal energy & 1.00 & 1.00 & 1.00 \\
Enthalpy & 1.00 & 1.00 & 1.00 \\
Gibbs-free & 1.00 & 1.00 & 1.00 \\
CV & 0.99 & 0.97 & 0.95 \\
Entropy & 0.98 & 0.95 & 0.92 \\
\hline
\end{tabular}

(Table 3). All the thermodynamic properties were computed at 298.150 Kelvin and pressure 1 Atm. The magnitude of the differences in thermodynamic properties (Table 2) shows that CCSD and PBE give closer values to MP2 than B3LYP. Also, considering the reproducibility of the order of bond distances obtained from MP2 in the other methods, all the computational methods produced a perfect order for the thermodynamic energies except PBE which gave a relatively better order for the $\mathrm{CV}$ and the entropy (Table 3). This is an indication that $\mathrm{PBE}$ performs better for geometrical optimization and computation of thermodynamic properties which agree well with the literatures that reported PBE correlation in combination with SBKJC VDZ ECP basis set as a good method for the optimization of metal complexes $[40,41]$. The computed types of energies using other methods of computation are higher in negative values than MP2, while their bond distance, $\mathrm{CV}$, and $\mathrm{S}$ are higher in positive values. Considering the RMSD of all the atoms in each of the models as shown in Table 4 and Figure 2, the optimized geometries obtained for the models $\mathrm{Ru}-\mathrm{C}, \mathrm{Ru}-\mathrm{O}$, and $\mathrm{Ru}-\mathrm{S}$ at various computational methods are very similar to lower RMSD compared to what was obtained for the models Ru-N, Ru$\mathrm{Cl}$, and Ru-P. Also, the RMSD of the optimized geometries obtained from the functional PBE are lower than those
TABLE 4: The RMSD of the optimized geometries obtained from other methods of computation from that obtained from MP2 using SBKJC VDZ ECP basis set.

\begin{tabular}{lccc}
\hline & B3LYP & CCSD & PBE \\
\hline Ru-C & 0.963 & 1.347 & 0.637 \\
$\mathrm{Ru}-\mathrm{N}$ & 1.030 & 1.032 & 1.035 \\
$\mathrm{Ru}-\mathrm{O}$ & 0.056 & 0.072 & 0.065 \\
$\mathrm{Ru}-\mathrm{Cl}$ & 1.302 & 1.030 & 1.268 \\
$\mathrm{Ru}-\mathrm{P}$ & 1.203 & 1.221 & 1.190 \\
$\mathrm{Ru}-\mathrm{S}$ & 0.265 & 0.266 & 0.252 \\
\hline
\end{tabular}

obtained from B3LYP and CCSD which further supports $\mathrm{PBE}$ as a good method for the optimization of ruthenium complexes.

3.2. Energy, HOMO, LUMO, Shielding Tensors, and JCoupling. The values of the energy, HOMO, LUMO, and isotropic and anisotropic shielding computed at MP2/aug-ccpVTZ and the variations obtained when computed with other methods are presented in Table 5. The shielding tensors were computed using Gauge-Independent Atomic Orbital (GIAO) method. The values of the energy and the variation obtained at different functional and basis sets show that variation in the energy values using different functional is lower compared to variation in the energy values using different basis sets. This is an indication that the energy values depend more on the type of basis sets rather than on the type of the functional. However, the variation in the values of HOMO, LUMO, and isotropic and anisotropic shielding at different functional methods shows that they depend more on the type of the functional and the geometrical change rather than on the type of the basis sets. The difference in the values of HOMO, LUMO, and isotropic and anisotropic shielding within MP2 methods at different basis set is lower compared to changing the functional to PBE and B3LYP. Also, B3LYP seems to perform better than PBE as the differences obtained at B3LYP are far lower compared to PBE. Also, considering the reproducibility of the order of these properties at different 
TABLE 5: The energy, shielding tensors, and J-coupling values using MP2/acc method and the differences using other computational methods (the energy values in Hartree).

\begin{tabular}{|c|c|c|c|c|c|c|c|}
\hline & Energy & HOMO & LUMO & $\mathrm{Ru}-\mathrm{Iso}$ & Ru-Aniso & $\mathrm{X}$-Iso & $\mathrm{X}$-Aniso \\
\hline Ru-C-MP2-acc & -4403.52 & -0.92 & -0.42 & -7421.80 & 10691.11 & -149.88 & 522.69 \\
\hline Ru-N-MP2-acc & -4418.77 & -0.90 & -0.46 & -11760.15 & 9465.97 & -825.79 & 1788.60 \\
\hline Ru-O-MP2-acc & -4439.24 & -0.68 & -0.18 & -9188.58 & 8466.75 & -166.94 & 1194.28 \\
\hline Ru-Cl-MP2-acc & -4823.19 & -0.62 & -0.20 & -11224.11 & 10522.28 & 298.22 & 2384.76 \\
\hline Ru-P-MP2-acc & -4705.44 & -0.87 & -0.37 & -13590.81 & 14885.90 & 448.61 & 41.41 \\
\hline Ru-S-MP2-acc & -4763.85 & -0.61 & -0.16 & -3133.38 & 5826.99 & -804.39 & 2375.77 \\
\hline \multicolumn{8}{|c|}{0.00} \\
\hline $\mathrm{Ru}-\mathrm{C}-\mathrm{MP} 2-\mathrm{dv}$ & -78.49 & 0.00 & 0.00 & 261.83 & -389.01 & 11.48 & 6.59 \\
\hline $\mathrm{Ru}-\mathrm{N}-\mathrm{MP} 2-\mathrm{dv}$ & -79.26 & 0.00 & -0.01 & 710.88 & -701.10 & 33.43 & -13.44 \\
\hline $\mathrm{Ru}-\mathrm{O}-\mathrm{MP} 2-\mathrm{dv}$ & -79.14 & 0.00 & 0.00 & -446.94 & -395.12 & -137.68 & 243.27 \\
\hline $\mathrm{Ru}-\mathrm{Cl}-\mathrm{MP} 2-\mathrm{dv}$ & -79.24 & 0.00 & 0.00 & -372.54 & 1144.75 & -197.16 & 354.79 \\
\hline Ru-P-MP2-dv & -79.57 & 0.00 & 0.00 & -1779.17 & 2465.57 & 25.18 & -0.37 \\
\hline $\mathrm{Ru}-\mathrm{S}-\mathrm{MP} 2-\mathrm{dv}$ & -77.19 & 0.02 & -0.02 & -6116.50 & 1355.58 & -205.80 & 358.51 \\
\hline Ru-C-MP2-ECP & 4268.78 & 0.00 & -0.01 & 5965.28 & -9200.85 & 13.11 & 1.93 \\
\hline Ru-N-MP2- ECP & 4268.00 & 0.00 & 0.00 & 9603.19 & -8131.49 & 74.35 & -74.55 \\
\hline Ru-O-MP2- ECP & 4268.12 & 0.00 & 0.00 & 7403.24 & -7159.56 & -82.99 & 156.74 \\
\hline Ru-Cl-MP2- ECP & 4268.02 & 0.00 & 0.00 & 9144.27 & -8674.35 & -164.84 & 411.30 \\
\hline Ru-P-MP2- ECP & 4267.70 & 0.00 & -0.01 & 10936.80 & -12181.57 & 32.60 & -13.17 \\
\hline Ru-S-MP2- ECP & 4270.07 & 0.03 & -0.03 & 1497.43 & -4965.80 & 137.97 & -144.94 \\
\hline $\mathrm{Ru}-\mathrm{C}-\mathrm{PBE}-\mathrm{dv}$ & -80.75 & 0.20 & -0.22 & -51.06 & -7670.06 & 349.29 & -461.55 \\
\hline Ru-N-PBE-dv & -81.56 & 0.18 & -0.20 & 6292.61 & -4964.09 & 526.42 & -926.41 \\
\hline Ru-O-PBE-dv & -81.47 & 0.22 & -0.18 & 138164.39 & 159842.43 & -3839.42 & 4139.74 \\
\hline Ru-Cl-PBE-dv & -81.76 & 0.15 & -0.18 & 103219.55 & 132875.50 & -4910.03 & 43707.95 \\
\hline Ru-P-PBE-dv & -82.01 & 0.21 & -0.21 & 165474.51 & 373242.21 & 3740.88 & 14462.38 \\
\hline Ru-S-PBE-dv & -79.73 & 0.18 & -0.19 & 106543.31 & 103474.55 & -6590.68 & 12307.39 \\
\hline Ru-C-PBE-ECP & 4267.64 & 0.21 & -0.21 & 6637.60 & -10275.35 & 75.97 & -170.75 \\
\hline Ru-N-PBE-ECP & 4266.81 & 0.18 & -0.20 & 10714.04 & -8849.98 & 530.35 & -933.20 \\
\hline Ru-O-PBE-ECP & 4266.90 & 0.22 & -0.18 & -33810.33 & 382779.43 & -30918.12 & 350412.47 \\
\hline Ru-Cl-PBE-ECP & 4266.60 & 0.15 & -0.18 & -7575.42 & 25794.02 & 271608.96 & \\
\hline Ru-P-PBE-ECP & 4266.35 & 0.21 & -0.21 & 191099.00 & 962614.33 & & \\
\hline Ru-S-PBE-ECP & 4268.63 & 0.18 & -0.19 & 95225.96 & 321193.44 & 115652.09 & 358353.34 \\
\hline Ru-C-B3LYP-dv & -81.28 & 0.16 & -0.18 & 812.27 & -5887.37 & 48.60 & -120.06 \\
\hline Ru-N-B3LYP-dv & -82.11 & 0.13 & -0.17 & 4319.91 & -2755.91 & 451.12 & -755.40 \\
\hline Ru-O-B3LYP-dv & -82.03 & 0.17 & -0.16 & 2733.24 & -3813.98 & -233.91 & 68.13 \\
\hline Ru-Cl-B3LYP-dv & -82.46 & 0.12 & -0.16 & 2548.50 & -2846.75 & -2658.07 & 3095.48 \\
\hline Ru-P-B3LYP-dv & -82.70 & 0.16 & -0.19 & 4725.61 & -6464.13 & -54.51 & 91.37 \\
\hline Ru-S-B3LYP-dv & -80.41 & 0.14 & -0.17 & -2259.01 & -2504.44 & 307.08 & -722.43 \\
\hline Ru-C-B3LYP-ECP & 4267.57 & 0.16 & -0.18 & 6249.66 & -10039.53 & 49.04 & -123.01 \\
\hline Ru-N-B3LYP-ECP & 4266.73 & 0.13 & -0.17 & 10402.50 & -8531.88 & 459.60 & -771.45 \\
\hline Ru-O-B3LYP-ECP & 4266.81 & 0.17 & -0.16 & 8020.53 & -7805.23 & -197.73 & -2.44 \\
\hline Ru-Cl-B3LYP-ECP & 4266.38 & 0.12 & -0.16 & 9776.24 & -9480.89 & -2364.64 & 2645.00 \\
\hline Ru-P-B3LYP-ECP & 4266.14 & 0.16 & -0.18 & 12079.02 & -13760.28 & -48.06 & 79.68 \\
\hline Ru-S-B3LYP-ECP & 4268.43 & 0.14 & -0.17 & 2124.24 & -5365.94 & 332.76 & -746.43 \\
\hline
\end{tabular}

MP2-acc stands for MP2/aug-cc-pVTZ, MP2-dv stands for MP2/DGDZVP, MP2-ECP stands for MP2/SBKJC VDZ, PBE-dv stands for PBE/DGDZVP, PBEECP stands for PBE/SBKJC VDZ, B3LYP-dv stands for B3LYP/DGDZVP, and B3LYP-ECP stands for B3LYP/SBKJC VDZ. 
TABLE 6: Correlation of other methods of computation with the MP2/acc in computing energy, HOMO, LUMO, and isotropic and anisotropic shielding.

\begin{tabular}{|c|c|c|c|c|c|c|}
\hline & MP2/DGDZVP & MP2/SBKJC VDZ & PBE/DGDZVP & PBE/SBKJC VDZ & B3LYP/DGDZVP & B3LYP/SBKJC VDZ \\
\hline Energy & 1.00 & 1.00 & 1.00 & 1.00 & 1.00 & 1.00 \\
\hline HOMO & 1.00 & 1.00 & 0.99 & 0.99 & 0.99 & 0.99 \\
\hline LUMO & 1.00 & 1.00 & 1.00 & 0.99 & 1.00 & 1.00 \\
\hline Ru-Iso & 0.74 & 0.83 & -0.09 & -0.11 & 0.91 & 0.94 \\
\hline Ru-Aniso & 0.95 & 0.97 & 0.51 & 0.50 & 0.84 & 0.82 \\
\hline $\mathrm{X}$-Iso & 0.98 & 0.98 & 0.67 & -0.51 & -0.16 & -0.12 \\
\hline $\mathrm{X}$-Aniso & 0.99 & 0.98 & -0.35 & 0.33 & 0.71 & 0.73 \\
\hline
\end{tabular}

TABLE 7: J-coupling of the Ru-L bonds at different level of computational methods.

\begin{tabular}{lcccc}
\hline & PBE/DGDZVP & PBE/SBKJC VDZ & B3LYP/DGDZVP & B3LYP/SBKJC VDZ \\
\hline $\mathrm{Ru}-\mathrm{C}$ & $-1.85 E+001$ & $1.14 E+000$ & $-2.68 E+000$ & $1.36 E+000$ \\
$\mathrm{Ru}-\mathrm{N}$ & $-1.46 E+001$ & $7.53 E-001$ & $6.56 E+001$ & $6.07 E+000$ \\
$\mathrm{Ru}-\mathrm{O}$ & $2.45 E+001$ & $-9.80 E-001$ & $2.49 E+001$ & $-1.17 E+000$ \\
$\mathrm{Ru}-\mathrm{Cl}$ & $4.72 E+001$ & $5.63 E+000$ & $4.76 E+001$ & $5.90 E+000$ \\
$\mathrm{Ru}-\mathrm{P}$ & $-6.51 E+001$ & $-3.14 E-001$ & $-7.14 E+001$ & $-5.00 E-001$ \\
$\mathrm{Ru}-\mathrm{S}$ & $-7.52 E-001$ & $1.06 E+000$ & $4.69 E-001$ & $1.35 E+000$ \\
\hline
\end{tabular}

TABLE 8: Correlation of $J$-coupling within the methods.

\begin{tabular}{lcccc}
\hline & PBE/DGDZVP & PBE/SBKJC VDZ & B3LYP/DGDZVP & B3LYP/SBKJC VDZ \\
\hline PBE-dv & 1.00 & 0.58 & 0.74 & 0.37 \\
PBE-ECP & 0.58 & 1.00 & 0.42 & 0.73 \\
B3LYP-dv & 0.74 & 0.42 & 1.00 & 0.72 \\
B3LYP-ECP & 0.37 & 0.73 & 0.72 & 1.00 \\
\hline
\end{tabular}

computational methods (Table 6), only the energy order is perfectly reproduced by all the methods. There is a very high similarity in the order of HOMO and LUMO, especially LUMO computed using B3LYP. In addition, B3LYP is found to also perform better in reproducing the shielding tensors of $\mathrm{Ru}$ and other atoms compared to PBE except for the order of the isotropic shielding of other atoms besides $\mathrm{Ru}$ atom. The correlation obtained from B3LYP in computing shielding tensors further supports its reported better performance for these properties [42].

In computation of the $J$-coupling, we are only limited to B3LYP and PBE since these properties are not permitted in Gaussian package at MP2 and CCSD level of theories. Considering the magnitude of $J$-coupling at B3LYP/DGDZVP, it follows the order Ru-P > Ru-N > Ru-Cl > Ru-S > Ru-O > $\mathrm{Ru}-\mathrm{C}$ (Table 7). The order is well reproduced in B3LYP with ECP basis set but is poor in PBE and is even the worst when PBE is combined with ECP basis set (Table 8). The simple reason for the variations is in support of the literature report demonstrating that the $J$-coupling is sensitive to bonding interactions [43].

3.3. Hyperpolarizability Properties. The values of the computed hyperpolarizabilities of the six models using different functionals and basis sets are shown in Table 9. The values of the hyperpolarizabilities of the models using MP2 functionals at different basis sets are in the order of $\mathrm{Ru}-\mathrm{S}>\mathrm{Ru}-\mathrm{O}>\mathrm{Ru}$ $\mathrm{Cl}>\mathrm{Ru}-\mathrm{N}>\mathrm{Ru}-\mathrm{P}>\mathrm{Ru}-\mathrm{C}$ which suggest the level of their possible modelling for NLO application. The order obtained from CCSD is $\mathrm{Ru}-\mathrm{O}>\mathrm{Ru}-\mathrm{Cl}>\mathrm{Ru}-\mathrm{S}>\mathrm{Ru}-\mathrm{P}>\mathrm{Ru}-\mathrm{N}>\mathrm{Ru}-$ $\mathrm{C}$; the $\mathrm{PBE}$ methods give the order $\mathrm{Ru}-\mathrm{Cl}>\mathrm{Ru}-\mathrm{C}<\mathrm{Ru}-\mathrm{S}>$ $\mathrm{Ru}-\mathrm{O}>\mathrm{Ru}-\mathrm{P}>\mathrm{Ru}-\mathrm{N}$ and B3LYP gives the order $\mathrm{Ru}-\mathrm{Cl}>$ $\mathrm{Ru}-\mathrm{O}>\mathrm{Ru}-\mathrm{S}>\mathrm{Ru}-\mathrm{P}>\mathrm{Ru}-\mathrm{N}>\mathrm{Ru}-\mathrm{C}$. The MP2 rated $\mathrm{Ru}-$ $\mathrm{S}$ as the best model for NLO application, while CCSD rated model $\mathrm{Ru}-\mathrm{O}$ as the best. Also, a different model, $\mathrm{Ru}-\mathrm{Cl}$, is indicated to have the highest hyperpolarizabilities using the functionals PBE and B3LYP irrespective of the basis set used. The correlations of the hyperpolarizabilities values among the models are shown in Table 10. The correlation table shows that the order of the hyperpolarizabilities of the models is perfectly reproducible using the same MP2 at different basis sets and also within CCSD at different basis sets. Also, B3LYP performs better in reproducing its order at different basis set compared to PBE. This clearly shows that the order of the hyperpolarizabilities depends greatly on the geometrical configuration and the type of the functional used rather than on the type of the basis sets. The only observed similarity in the order of the hyperpolarizabilities computed with different methods is that all the methods rated the models $\mathrm{Ru}-\mathrm{S}, \mathrm{Ru}-$ $\mathrm{Cl}$, and Ru-O among the best three except for PBE which excluded $\mathrm{Ru}-\mathrm{O}$ from its best three.

3.4. The IR Vibrations. The IR vibrations of the models at different computational methods are shown in Figure 3. The vibrations which are of significant interest to us are their Ru-ligand bonds of Ru-C, Ru-N, Ru-O, Ru-Cl, Ru-P, and $\mathrm{Ru}-\mathrm{S}$ which are shown in Table 11. Also, most of the prominent vibrations are assigned as shown in Table 12. In 


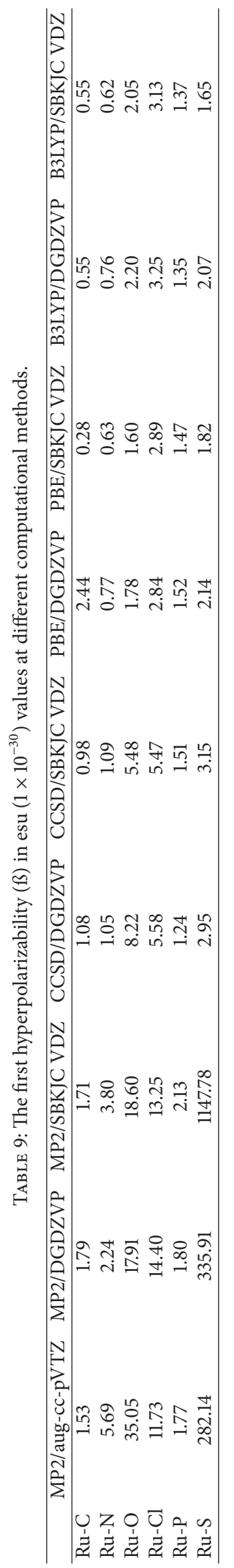




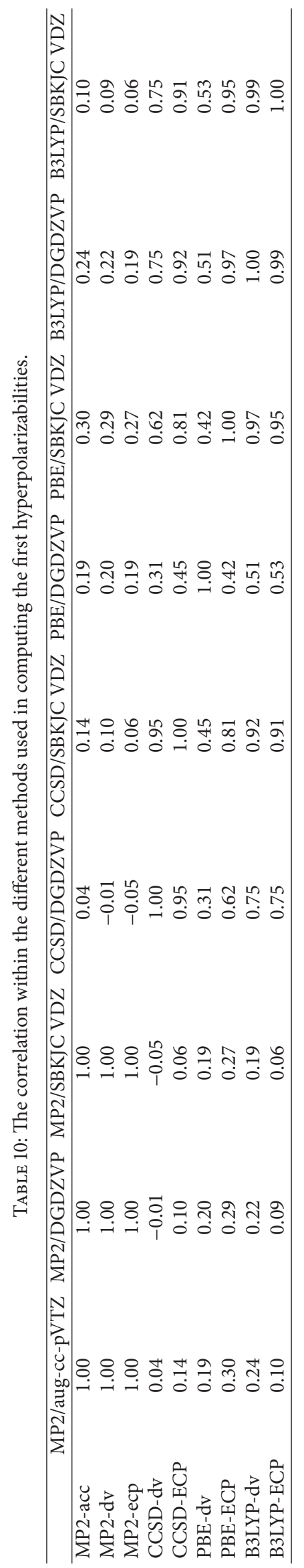



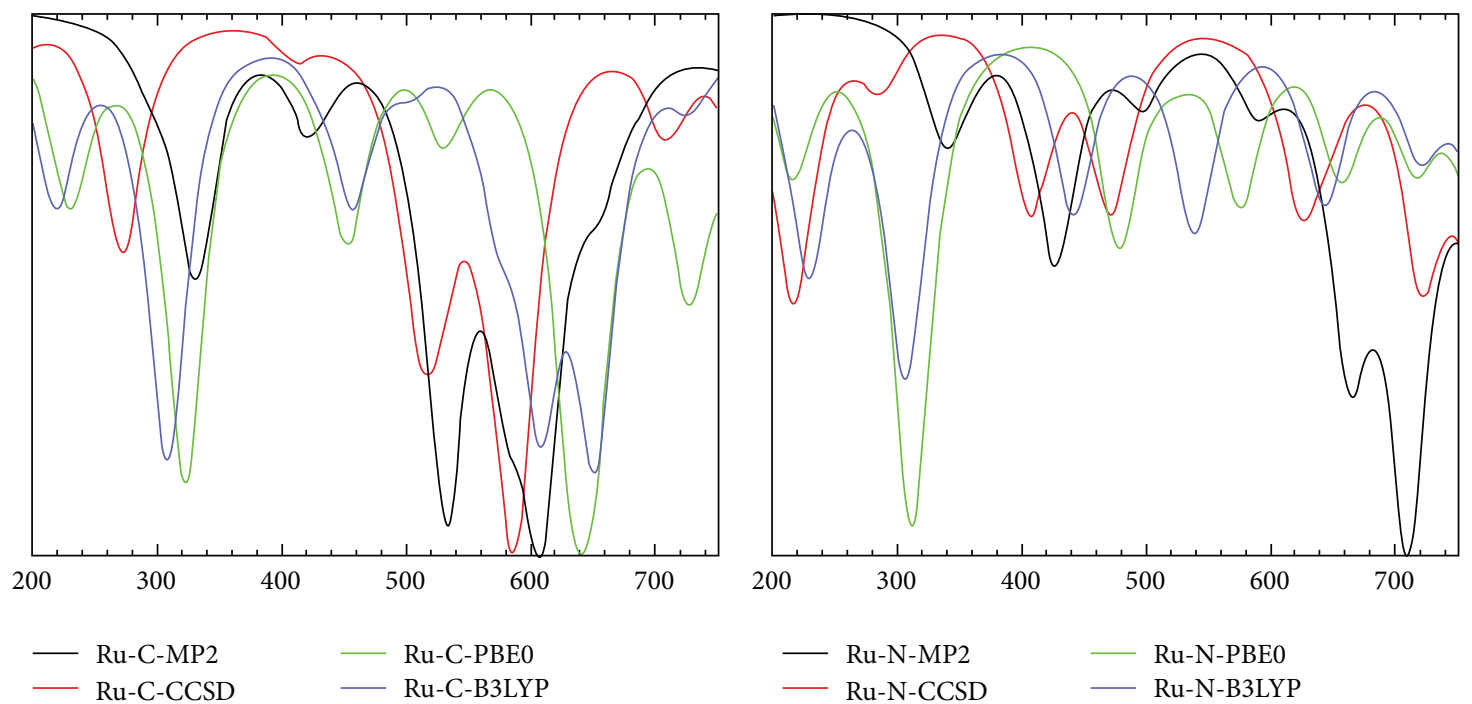

$\begin{array}{ll}- \text { Ru-N-MP2 } & - \text { Ru-N-PBE0 } \\ \text { Ru-N-CCSD } & \text { Ru-N-B3LYP }\end{array}$
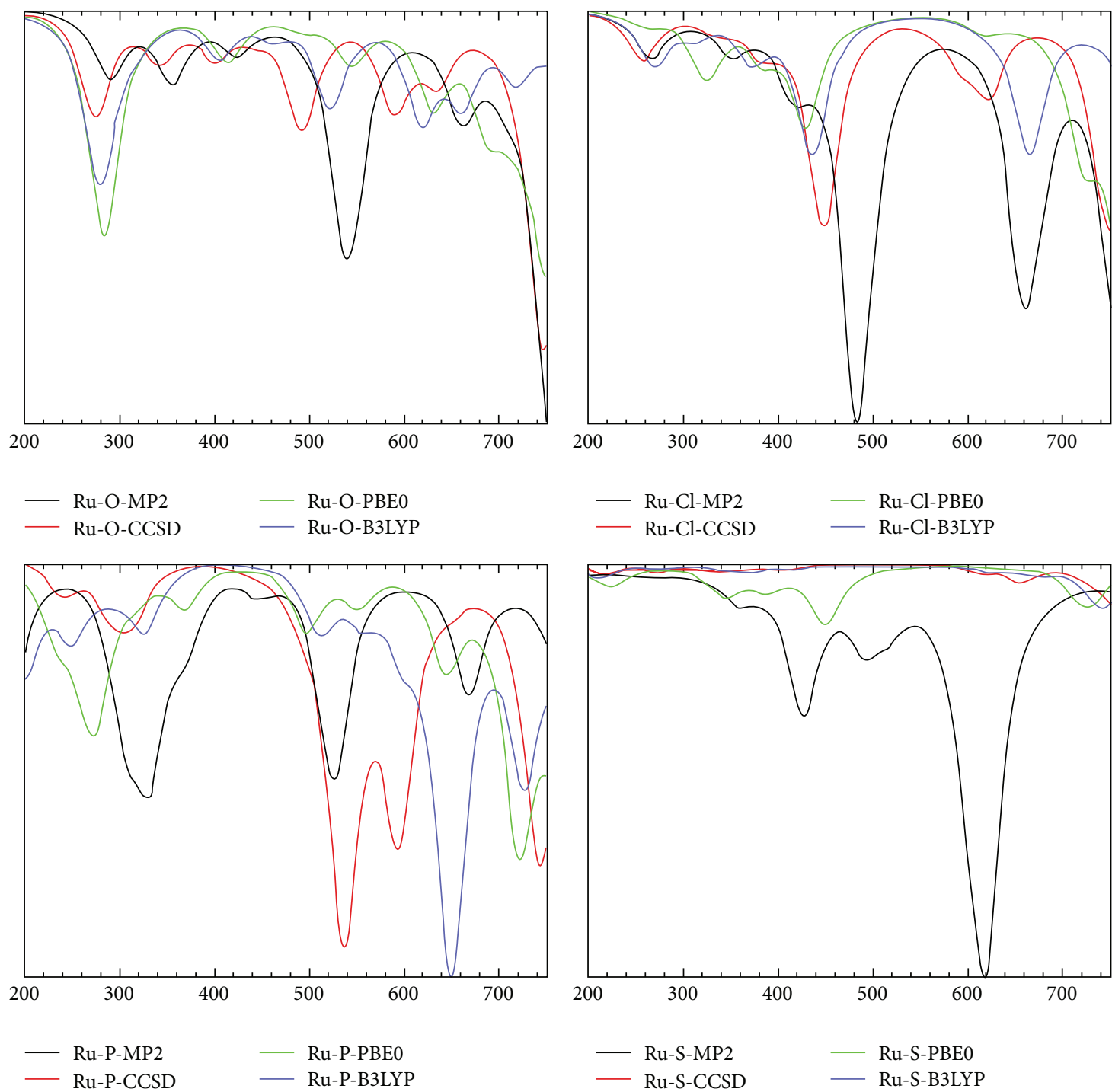

FIGURE 3: The IR vibrations of the six models computed using MP2 (black), CCSD (red), PBE (green), and B3LYP (blue). 


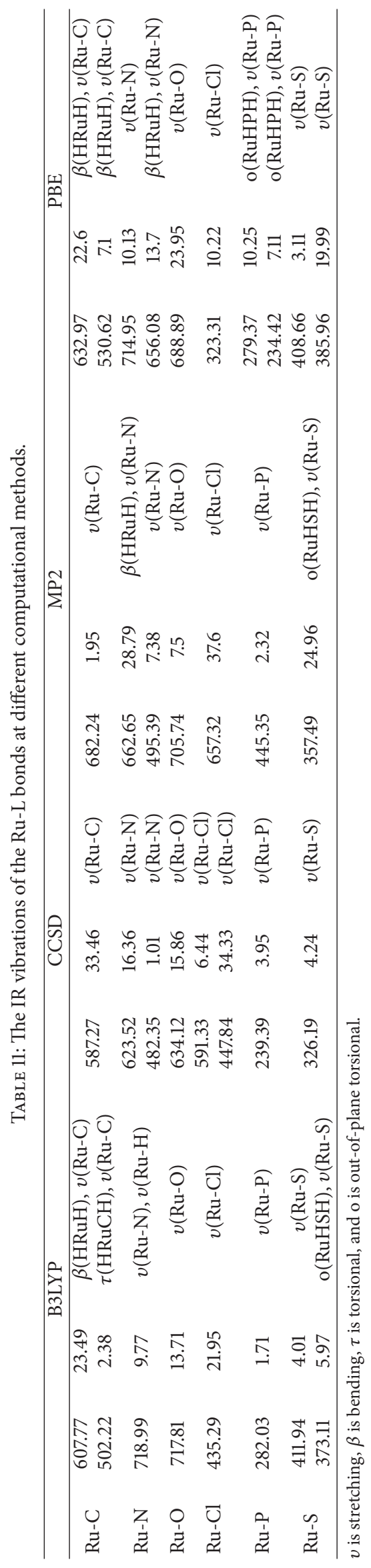




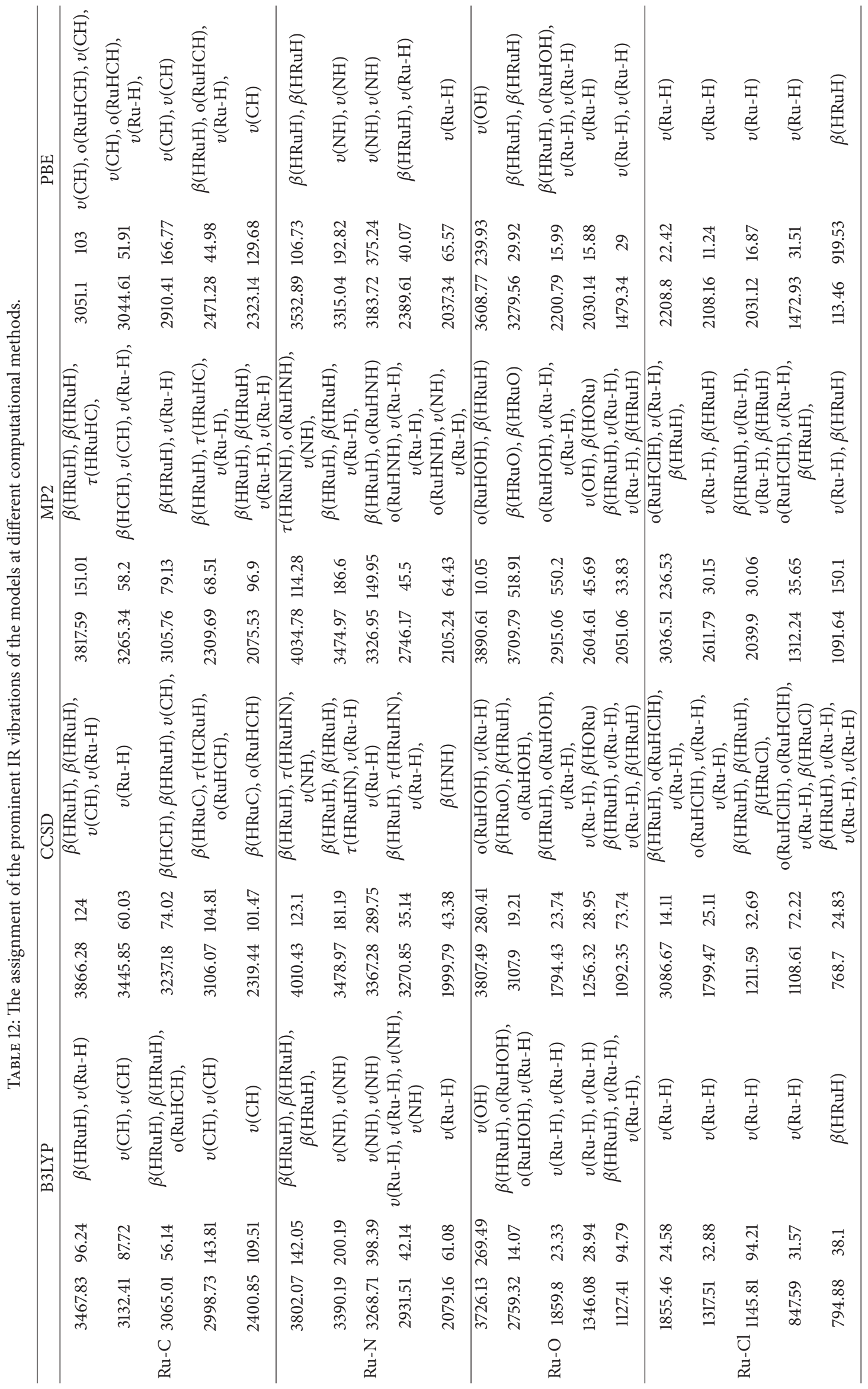




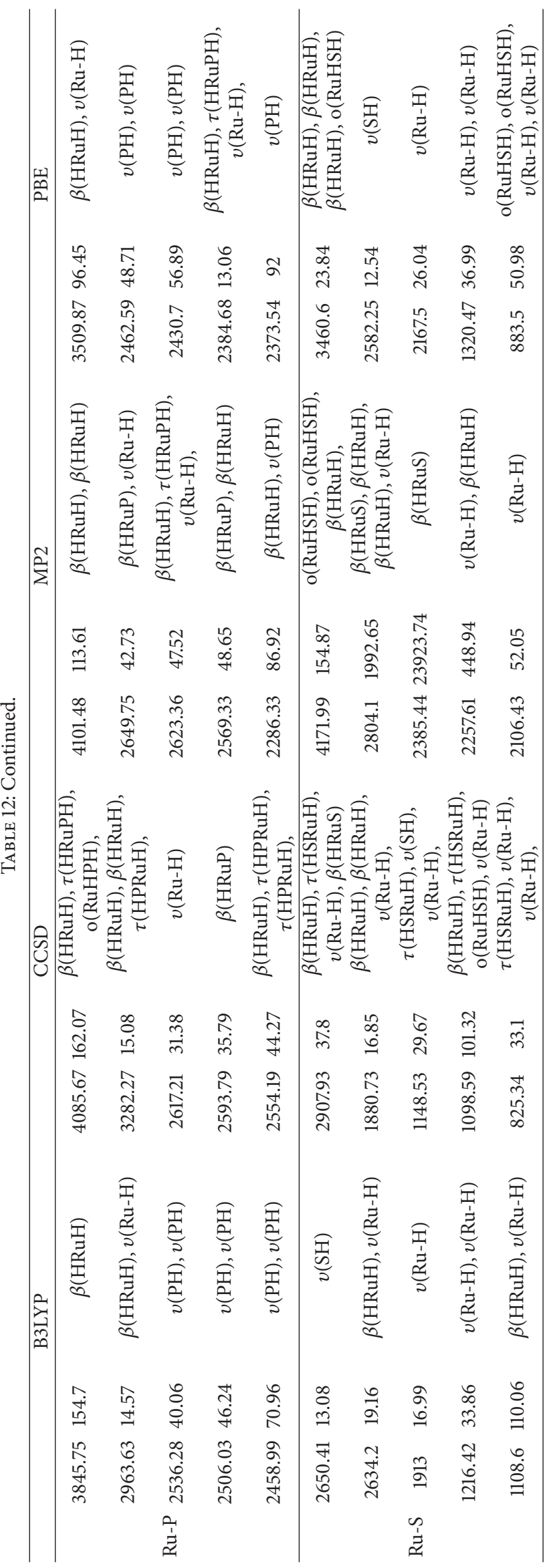


all the methods, $\mathrm{Ru}-\mathrm{C}, \mathrm{Ru}-\mathrm{N}$, and $\mathrm{Ru}-\mathrm{O}$ vibrations are within the range of 500 to 720 which is far higher than the range of vibrations of $\mathrm{Ru}-\mathrm{Cl}, \mathrm{Ru}-\mathrm{P}$, and $\mathrm{Ru}-\mathrm{S}$ which are found within the range of 224 to 658 . Generally, the order of $\mathrm{Ru}-$ $\mathrm{L}$ vibrations can be assumed as $\mathrm{Ru}-\mathrm{N}>\mathrm{Ru}-\mathrm{O}>\mathrm{Ru}-\mathrm{C}>$ $\mathrm{Ru}-\mathrm{Cl}>\mathrm{Ru}-\mathrm{S}>\mathrm{Ru}-\mathrm{P}$ (Table 11). The wavenumbers of the vibrations computed from the different methods appear to be significantly different from each other in values and positions (Figure 3). The features of the IR spectra using MP2 and CCSD are very similar in the models. Some vibration around 2915.06 in model $\mathrm{Ru}-\mathrm{O}, 3036.51$ in $\mathrm{Ru}-\mathrm{Cl}$, and 2385.44 in $\mathrm{Ru}-\mathrm{S}$ are very prominent in MP2 methods compared to in any other methods or even absent in other methods. For instance, the bending of the angle of HRuS which is found to be prominent in MP2 method is completely absent in other methods (see Figure 3 and Table 12). The MP2 and CCSD show strong vibrations within the range of 3800 to 4100 in many of the models which are obviously absent in many of the PBE and B3LYP methods. Using the PED method as implemented in VEDA package, most of these vibrations at high frequencies are a result of the torsional and out-ofplane vibration of $\mathrm{H}-\mathrm{Ru}-\mathrm{X}-\mathrm{H}$, where $\mathrm{X}$ represents the type of the model as shown in Table 12. In addition, most of the bending vibrations which are determined by PBE and B3LYP from 2800 to 3800 in the models are also determined by MP2 and CCSD, though some cases are at lower wavenumber compared to PBE and B3LYP (Table 12). In the models Ru-O and $\mathrm{Ru}-\mathrm{Cl}, \mathrm{PBE}$ and B3LYP give priority to the $\mathrm{OH}$ and $\mathrm{RuH}$ vibrations, respectively, while MP2 and CCSD give priority to the torsional stretching and angle bending of their atoms.

\section{Conclusions}

Six models of Ru-L bonds, $\mathrm{Ru}-\mathrm{C}, \mathrm{Ru}-\mathrm{N}, \mathrm{Ru}-\mathrm{O}, \mathrm{Ru}-\mathrm{Cl}, \mathrm{Ru}-$ $\mathrm{P}$, and $\mathrm{Ru}-\mathrm{S}$, are built to represent common ruthenium complexes and possible ruthenium-receptor interactions. The reproducibility of their geometrical, electronic, spectroscopic, and conductive properties was investigated using MP2, CCSD, PBE, and B3LYP functionals with different combination of basis sets. Generally, we observed that the reproducibility of most of the properties is much easier using different basis sets compared to using different functional methods as a result of significant geometrical changes which is possible especially if there are many light atoms like hydrogen atoms as in the models. The order of the energy and the thermodynamic properties are found to be reproducible using different functional methods and basis sets but HOMO, LUMO, J-coupling, hyperpolarizabilities, and isotropic and anisotropic shielding are found to depend more on the type of the functional used rather than on the type of the basis set. The only significant similarity observed among the methods applied in computing hyperpolarizabilities is that they all rated models $\mathrm{Ru}-\mathrm{S}, \mathrm{Ru}-\mathrm{Cl}$, and $\mathrm{Ru}-\mathrm{O}$ among their best three. The optimized geometries and the thermodynamic properties obtained from the functional $\mathrm{PBE}$ are found to be very similar to MP2 and perform better than B3LYP and CCSD which further give insight into many literatures' preference for PBE in optimizing metal complexes. In computation of the isotropic and anisotropic shielding tensors, B3LYP gives values similar to MP2 and performs better than PBE. The IR vibrations and assignment clearly show that the vibrations obtained from the MP2 and CCSD methods are very similar and give preference to the torsional and bending vibrations of the molecules over their stretching. The order of the IR vibrations of the ruthenium-ligand bonds can be assumed as $\mathrm{Ru}-\mathrm{N}>\mathrm{Ru}-\mathrm{O}>\mathrm{Ru}-\mathrm{C}>\mathrm{Ru}-\mathrm{Cl}>\mathrm{Ru}-\mathrm{S}>\mathrm{Ru}-\mathrm{P}$.

\section{Conflict of Interests}

The authors declare that there is no conflict of interests regarding the publication of this paper.

\section{Acknowledgments}

The authors gracefully acknowledged the financial support of Govan Mbeki Research and Development Centre, University of Fort Hare, South Africa. The CHPC in Republic of South Africa is gracefully acknowledged for providing the computing facilities and some of the software used for the computation.

\section{References}

[1] B. Dutta, R. Scopelliti, and K. Severin, "Synthesis, structure, and reactivity of the methoxy-bridged dimer $\left[\mathrm{Cp}^{\wedge} \mathrm{Ru}(\mu-\mathrm{OMe})\right]_{2}$ $\left(\mathrm{Cp}^{\wedge}=\eta^{5}\right.$-1-methoxy-2,4-di-tert-butyl-3-neopentylcyclopentadienyl)," Organometallics, vol. 27, no. 3, pp. 423-429, 2008.

[2] M. A. Furrer, F. Schmitt, M. Wiederkehr, L. Juillerat-Jeanneret, and B. Therrien, "Cellular delivery of pyrenyl-arene ruthenium complexes by a water-soluble arene ruthenium metalla-cage," Dalton Transactions, vol. 41, no. 24, pp. 7201-7211, 2012.

[3] Q. Zhou, W. Lei, Y. Chen et al., "Ruthenium(II)-arene complexes with strong fluorescence: insight into the underlying mechanism," Chemistry - A European Journal, vol. 18, no. 28, pp. 86178621, 2012.

[4] L. Bíró, E. Farkas, and P. Buglyó, "Hydrolytic behaviour and chloride ion binding capability of $\left[\mathrm{Ru}\left(\eta^{6}-p-\operatorname{cym}\right)\left(\mathrm{H}_{2} \mathrm{O}\right)_{3}\right]^{2+}$ : a solution equilibrium study," Dalton Transactions, vol. 41, no. 1, pp. 285-291, 2012.

[5] Y. Boutadla, D. L. Davies, R. C. Jones, and K. Singh, "The scope of ambiphilic acetate-assisted cyclometallation with halfsandwich complexes of iridium, rhodium and ruthenium," Chemistry - A European Journal, vol. 17, no. 12, pp. 3438-3448, 2011.

[6] Y. F. Han, H. Li, Y. Fei, Y. J. Lin, W. Z. Zhang, and G. $\mathrm{X}$. Jin, "Synthesis and structural characterization of binuclear half-sandwich iridium, rhodium and ruthenium complexes containing 4,4'-dipyridyldisulfide (4DPDS) ligands," Dalton Transactions, vol. 39, no. 30, pp. 7119-7124, 2010.

[7] B. Dutta, B. F. Curchod, P. Campomanes et al., "Reactions of alkynes with [RuCl(cyclopentadienyl)] complexes: the important first steps," Chemistry-A European Journal, vol. 16, no. 28, pp. 8400-8409, 2010.

[8] M. Jiménez-Tenorio, M. C. Puerta, P. Valerga, S. Moncho, G. Ujaque, and A. Lledós, "Proton-transfer reactions to halfsandwich ruthenium trihydride complexes bearing hemilabile P,N ligands: experimental and density functional theory studies," Inorganic Chemistry, vol. 49, no. 13, pp. 6035-6057, 2010. 
[9] B. Dutta, C. Scolaro, R. Scopelliti, P. J. Dyson, and K. Severin, "Importance of the $\pi$-ligand: remarkable effect of the cyclopentadienyl ring on the cytotoxicity of ruthenium PTA compounds," Organometallics, vol. 27, no. 7, pp. 1355-1357, 2008.

[10] T. Bugarcic, A. Habtemariam, J. Stepankova et al., "The contrasting chemistry and cancer cell cytotoxicity of bipyridine and bipyridinediol ruthenium(II) arene complexes," Inorganic Chemistry, vol. 47, no. 24, pp. 11470-11486, 2008.

[11] M. Castellano-Castillo, H. Kostrhunova, V. Marini et al., "Binding of mismatch repair protein MutS to mispaired DNA adducts of intercalating ruthenium(II) arene complexes," Journal of Biological Inorganic Chemistry, vol. 13, no. 6, pp. 993-999, 2008.

[12] S. J. Dougan, A. Habtemariam, S. E. McHale, S. Parsons, and P. J. Sadler, "Catalytic organometallic anticancer complexes," Proceedings of the National Academy of Sciences of the United States of America, vol. 105, no. 33, pp. 11628-11633, 2008.

[13] S. J. Dougan, M. Melchart, A. Habtemariam, S. Parsons, and P. J. Sadler, "Phenylazo-pyridine and phenylazo-pyrazole chlorido ruthenium(II) arene complexes: arene loss, aquation, and cancer cell cytotoxicity," Inorganic Chemistry, vol. 45, no. 26, pp. 10882-10894, 2006.

[14] V. Ritleng, P. Bertani, M. Pfeffer, C. Sirlin, and J. Hirschinger, "Optically active ortho-metalated half-sandwich ruthenium complexes: solid-state NMR as a convenient tool to analyze mixtures of diastereomers," Inorganic Chemistry, vol. 40, no. 20, pp. 5117-5122, 2001.

[15] Y. Sunada, Y. Hayashi, H. Kawaguchi, and K. Tatsumi, "Alkynethiolato and alkyneselenolato ruthenium half-sandwich complexes: Synthesis, structures, and reactions with ( $\eta 5-$ C5H5)2Zr," Inorganic Chemistry, vol. 40, no. 27, pp. 7072-7078, 2001.

[16] K. Yamanari, R. Ito, S. Yamamoto et al., "Cyclic tetramers composed of rhodium(III), iridium(III), or ruthenium(II) halfsandwich and 6-purinethiones," Inorganic Chemistry, vol. 41, no. 25, pp. 6824-6830, 2002.

[17] F. Caruso, M. Rossi, A. Benson et al., "Ruthenium-arene complexes of curcumin: X-ray and density functional theory structure, synthesis, and spectroscopic characterization, in vitro antitumor activity, and DNA docking studies of ( $p$ cymene) $\mathrm{Ru}$ (curcuminato)chloro," Journal of Medicinal Chemistry, vol. 55, no. 3, pp. 1072-1081, 2012.

[18] C. Gossens, I. Tavernelli, and U. Rothlisberger, "Binding of organometallic ruthenium(II) anticancer compounds to nucleobases: a computational study," Journal of Physical Chemistry A, vol. 113, no. 43, pp. 11888-11897, 2009.

[19] A. M. Pizarro, A. Habtemariam, and P. J. Sadler, "Activation mechanisms for organometallic anticancer complexes," in Medicinal Organometallic Chemistry, vol. 32 of Topics in Organometallic Chemistry, pp. 21-56, Springer, Berlin, Germany, 2010.

[20] I. Turel and J. Kljun, "Interactions of metal ions with DNA, its constituents and derivatives, which may be relevant for anticancer research," Current Topics in Medicinal Chemistry, vol. 11, no. 21, pp. 2661-2687, 2011.

[21] G. Gasser, I. Ott, and N. Metzler-Nolte, "Organometallic anticancer compounds," Journal of Medicinal Chemistry, vol. 54, no. 1, pp. 3-25, 2011.

[22] K. J. Kilpin, S. Crot, T. Riedel, J. A. Kitchen, and P. J. Dyson, "Ruthenium(II) and osmium(II) 1,2,3-triazolylidene organometallics: a preliminary investigation into the biological activity of 'click' carbene complexes,' Dalton Transactions, vol. 43, no. 3, pp. 1443-1448, 2014.
[23] A. F. A. Peacock, S. Parsons, and P. J. Sadler, "Tuning the hydrolytic aqueous chemistry of osmium arene complexes with N,O-chelating ligands to achieve cancer cell cytotoxicity," Journal of the American Chemical Society, vol. 129, no. 11, pp. 3348-3357, 2007.

[24] A. F. A. Peacock, M. Melchart, R. J. Deeth, A. Habtemariam, S. Parsons, and P. J. Sadler, "Osmium(II) and ruthenium(II) arene maltolato complexes: rapid hydrolysis and nucleobase binding," Chemistry-A European Journal, vol. 13, no. 9, pp. 2601-2613, 2007.

[25] F. Pelletier, V. Comte, A. Massard et al., "Development of bimetallic titanocene-ruthenium-arene complexes as anticancer agents: relationships between structural and biological properties," Journal of Medicinal Chemistry, vol. 53, no. 19, pp. 6923-6933, 2010.

[26] K. J. Kilpin and P. J. Dyson, "Enzyme inhibition by metal complexes: concepts, strategies and applications," Chemical Science, vol. 4, no. 4, pp. 1410-1419, 2013.

[27] G. Gasser and N. Metzler-Nolte, "The potential of organometallic complexes in medicinal chemistry," Current Opinion in Chemical Biology, vol. 16, no. 1-2, pp. 84-91, 2012.

[28] I. Turel, J. Kljun, F. Perdih et al., "First ruthenium organometallic complex of antibacterial agent ofloxacin. Crystal structure and interactions with DNA," Inorganic Chemistry, vol. 49, no. 23, pp. 10750-10752, 2010.

[29] C. Adamo and V. Barone, "Toward reliable density functional methods without adjustable parameters: the PBE0 model," Journal of Chemical Physics, vol. 110, no. 13, pp. 6158-6170, 1999.

[30] A. D. Becke, "Density-functional thermochemistry. III. The role of exact exchange," The Journal of Chemical Physics, vol. 98, no. 7, article 5648, 1993.

[31] W. J. Stevens, M. Krauss, H. Basch, and P. G. Jasien, "Relativistic compact effective potentials and efficient, shared-exponent basis sets for the third-, fourth-, and fifth-row atoms," Canadian Journal of Chemistry, vol. 70, no. 2, pp. 612-630, 1992.

[32] M. J. Frisch, G. W. Trucks, H. B. Schlegel et al., Official Gaussian 09 Literature Citation, Gaussian, Wallingford, UK, 2009.

[33] D. J. Feller, "The role of databases in support of computational chemistry calculations," Journal of Computational Chemistry, vol. 17, no. 13, pp. 1571-1586, 1996.

[34] K. L. Schuchardt, B. T. Didier, T. Elsethagen et al., "Basis set exchange: a community database for computational sciences," Journal of Chemical Information and Modeling, vol. 47, no. 3, pp. 1045-1052, 2007.

[35] Y. Liu, C.-G. Liu, S.-L. Sun, G.-C. Yang, and Y.-Q. Qiu, "Redox-switching second-order nonlinear optical responses of $\mathrm{N}^{\wedge} \mathrm{N}^{\wedge} \mathrm{N}$ ruthenium complexes," Computational and Theoretical Chemistry, vol. 979, pp. 112-118, 2012.

[36] P. S. Liyanage, R. M. de Silva, and K. M. N. de Silva, "Nonlinear optical (NLO) properties of novel organometallic complexes: high accuracy density functional theory (DFT) calculations," Journal of Molecular Structure: THEOCHEM, vol. 639, pp. 195201, 2003.

[37] M. H. Jamróz, "Vibrational Energy Distribution Analysis: VEDA 4, Program," Warsaw, Poland, 2004-2010, http://www.smmg.pl/.

[38] M. H. Jamróz, J. C. Dobrowolski, and R. Brzozowski, "Vibrational modes of 2,6-, 2,7-, and 2,3-diisopropylnaphthalene. A DFT study," Journal of Molecular Structure, vol. 787, no. 1-3, pp. 172-183, 2006.

[39] M. H. Jamróz, "Vibrational Energy Distribution Analysis (VEDA): scopes and limitations," Spectrochimica Acta A: Molecular and Biomolecular Spectroscopy, vol. 114, pp. 220-230, 2013. 
[40] R. Marchal, P. Carbonnière, D. Begue, and C. Pouchan, "Structural and vibrational determination of small gallium-arsenide clusters from CCSD(T) and DFT calculations," Chemical Physics Letters, vol. 453, no. 1-3, pp. 49-54, 2008.

[41] R. Marchal, P. Carbonnière, and C. Pouchan, "Structural and vibrational properties prediction of $\mathrm{Sn}_{n} \mathrm{Te}_{n}$ clusters $(n=2-$ 8) using the GSAM approach," Computational and Theoretical Chemistry, vol. 990, pp. 100-105, 2012.

[42] T. Helgaker, M. Jaszuński, and M. Pecul, "The quantumchemical calculation of NMR indirect spin-spin coupling constants," Progress in Nuclear Magnetic Resonance Spectroscopy, vol. 53, no. 4, pp. 249-268, 2008.

[43] F. A. Perras and D. L. Bryce, "Theoretical study of homonuclear J coupling between quadrupolar spins: single-crystal, DOR, and $J$-resolved NMR," Journal of Magnetic Resonance, vol. 242, pp. 23-32, 2014.

[44] I. D. Burns, A. F. Hill, A. J. P. White, D. J. Williams, and J. D. E. T. Wilton-Ely, "Polyazolyl chelate chemistry. 6.1 bidentate coordination of $\mathrm{HB}(\mathrm{pz})_{3}(\mathrm{pz}=$ Pyrazol-1-yl) to ruthenium and osmium: crystal structure of $\left[\mathrm{RuH}(\mathrm{CO})\left(\mathrm{PPh}_{3}\right)_{2}\left\{\mathrm{k}^{2}-\mathrm{HB}(\mathrm{pz})_{3}\right\}\right]$," Organometallics, vol. 17, no. 8, pp. 1552-1557, 1998.

[45] M. Al-Noaimi and M. A. AlDamen, "Ruthenium complexes incorporating azoimine and $\alpha$-diamine based ligands: synthesis, crystal structure, electrochemistry and DFT calculation," Inorganica Chimica Acta, vol. 387, pp. 45-51, 2012.

[46] K. Nakajima, Y. Ando, H. Mano, and M. Kojima, "Photosubstitution reactivity, crystal structures, and electrochemistry of ruthenium(II) (III) complexes containing tetradentate $\left(\mathrm{O}_{2} \mathrm{~N}_{2}\right.$, $\mathrm{S}_{2} \mathrm{~N}_{2}$, and $\mathrm{P}_{2} \mathrm{~N}_{2}$ ) Schiff base ligands," Inorganica Chimica Acta, vol. 274, no. 2, pp. 184-191, 1998.

[47] Z.-L. Lu, K. Eichele, I. Warad et al., "Supported organometallic complexes XXXVIII [1]. Bis(methoxyethyldimethlphosphine)ruthenium(II) complexes as transfer hydrogenation catalysts," Zeitschrift für Anorganische und Allgemeine Chemie, vol. 629, no. 7-8, pp. 1308-1315, 2003.

[48] R. Gaur and L. Mishra, "Synthesis and characterization of $\mathrm{Ru}(\mathrm{II})-\mathrm{DMSO}-\mathrm{Cl}-$ chalcone complexes: DNA binding, nuclease, and topoisomerase II inhibitory activity," Inorganic Chemistry, vol. 51, no. 5, pp. 3059-3070, 2012.

[49] B. Cebrián-Losantos, E. Reisner, C. R. Kowol et al., "Synthesis and reactivity of the aquation product of the antitumor complex trans- $\left[\mathrm{Ru}^{\mathrm{III}} \mathrm{CI}_{4} \text { (indazole) }{ }_{2}\right]^{-,}$, Inorganic Chemistry, vol. 47, no. 14, pp. 6513-6523, 2008.

[50] B. T. Rasley, M. Rapta, and R. J. Kulawiec, "Diastereoselectivity in enolate coordination in a new class of chiral ruthenium enolate complexes," Organometallics, vol. 15, no. 13, pp. 28522854, 1996.

[51] S. David, R. S. Perkins, F. R. Fronczek, S. Kasiri, S. S. Mandal, and R. S. Srivastava, "Synthesis, characterization, and anticancer activity of ruthenium-pyrazole complexes," Journal of Inorganic Biochemistry, vol. 111, pp. 33-39, 2012.

[52] B. Dutta, E. Solari, S. Gauthier, R. Scopelliti, and K. Severin, "Ruthenium half-sandwich complexes with sterically demanding cyclopentadienyl ligands," Organometallics, vol. 26, no. 19, pp. 4791-4799, 2007.

[53] G. Türkoglu, S. Tampier, F. Strinitz, F. W. Heinemann, E. Hübner, and N. Burzlaff, "Ruthenium carbonyl complexes bearing bis(pyrazol-1-yl)carboxylato ligands," Organometallics, vol. 31, no. 6, pp. 2166-2174, 2012.

[54] A. K. Renfrew, A. D. Phillips, E. Tapavicza, R. Scopelliti, U. Rothlisberger, and P. J. Dyson, "Tuning the efficacy of
ruthenium(II)-arene (RAPTA) antitumor compounds with fluorinated arene ligands," Organometallics, vol. 28, no. 17, pp. 5061-5071, 2009.

[55] P. M. Jeffries, R. E. Ellenwood, and G. S. Girolami, "Anionic ruthenium(II) alkyls with ancillary diene and dienyl ligands: synthesis and structures of $\left[\left(\eta^{2}, \eta^{2}-\mathrm{C}_{7} \mathrm{H}_{8}\right) \mathrm{RuMe}_{4}\right]^{2-}$ and $\left[\left(\eta^{3}, \eta^{2}-\right.\right.$ $\left.\left.\mathrm{C}_{8} \mathrm{H}_{11}\right) \mathrm{RuMe}_{3}\right]^{2-}$," Inorganica Chimica Acta, vol. 361, no. 1, pp. 3165-3170, 2008.

[56] B. R. James, D. Dolphin, T. W. Leung, F. W. B. Einstein, and A. C. Willis, "Preparation and characterization of some ruthenium(III) porphyrins, including the crystal structure of bromo(octaethylporphinato)(triphenylphosphine)ruthenium(III)," Canadian Journal of Chemistry, vol. 62, no. 7, pp. 1238-1245, 1984.

[57] M. Plois, R. Wolf, W. Hujo, and S. Grimme, "Towards reagents for bimetallic activation reactions: polyhydride complexes with $\mathrm{Ru}_{2} \mathrm{H}_{3}, \mathrm{Ru}_{2} \mathrm{ZnH}_{6}$, and $\mathrm{Cu}_{2} \mathrm{Ru}_{2} \mathrm{H}_{6}$ cores," European Journal of Inorganic Chemistry, vol. 2013, no. 17, pp. 3039-3048, 2013.

[58] L. Hintermann, L. Xiao, A. Labonne, and U. Englert, "[CpRu$\left(\eta^{6}\right.$-naphthalene $\left.)\right] \mathrm{PF}_{6}$ as precursor in complex synthesis and catalysis with the cyclopentadienyl-ruthenium(II) cation," Organometallics, vol. 28, no. 19, pp. 5739-5748, 2009.

[59] I. W. Wyman, K. N. Robertson, T. S. Cameron, J. C. Swarts, and M. A. S. Aquino, "Synthesis, structure and electrochemistry of (ferrocene-2-propenoato-O,O' )bis[1,2-bis(diphenylphosphino)ethane-P, $\mathrm{P}^{\prime}$ ]ruthenium(II) hexafluorophosphate," Inorganica Chimica Acta, vol. 359, no. 9, pp. 3092-3096, 2006.

[60] C. A. Vock, C. Scolaro, A. D. Phillips, R. Scopelliti, G. Sava, and P. J. Dyson, "Synthesis, characterization, and in vitro evaluation of novel ruthenium(II) $\eta^{6}$-arene imidazole complexes," Journal of Medicinal Chemistry, vol. 49, no. 18, pp. 5552-5561, 2006. 

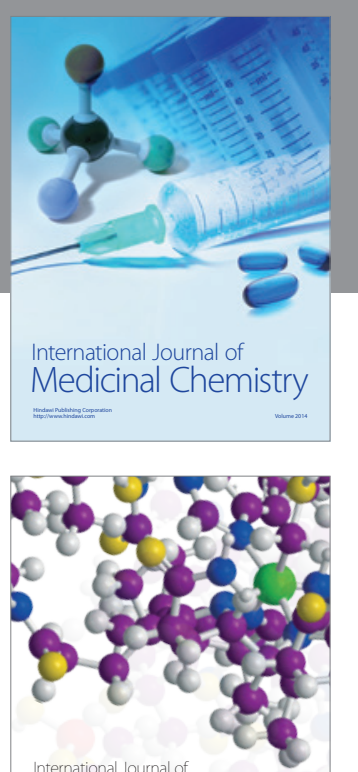

Carbohydrate Chemistry

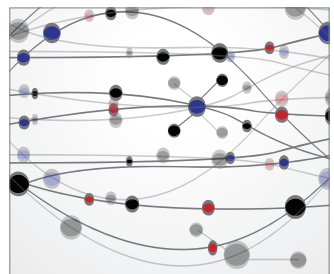

The Scientific World Journal
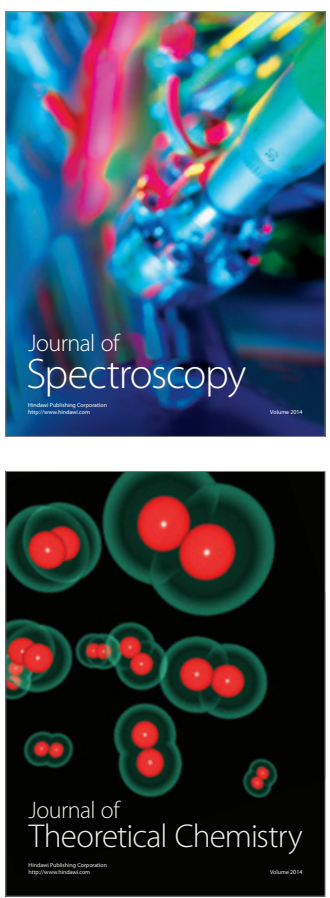
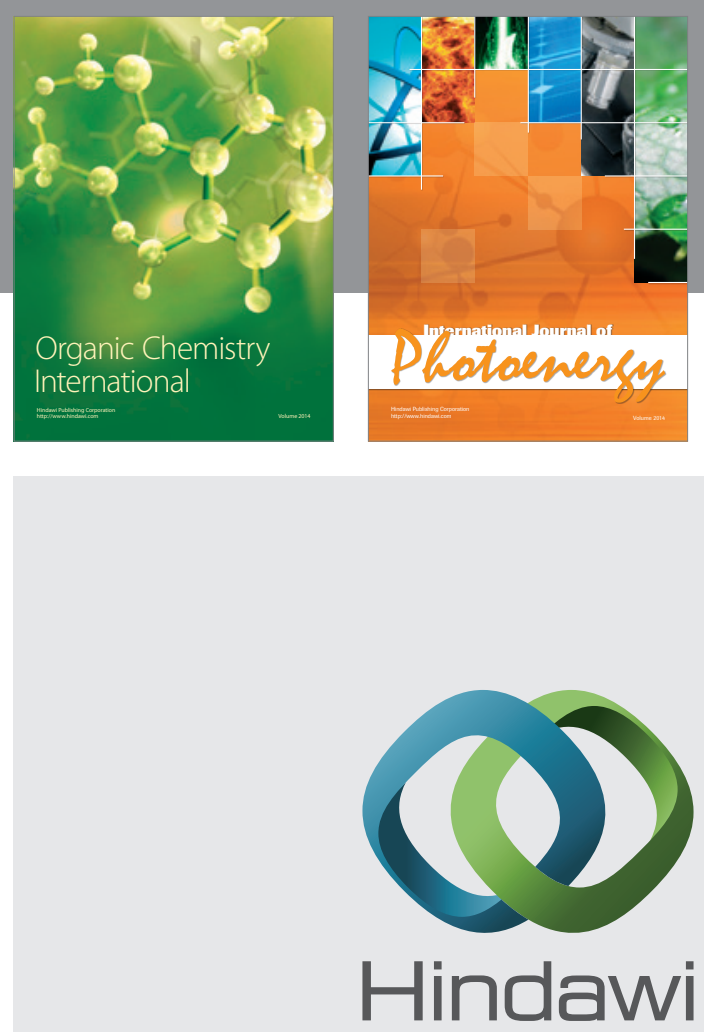

Submit your manuscripts at

http://www.hindawi.com

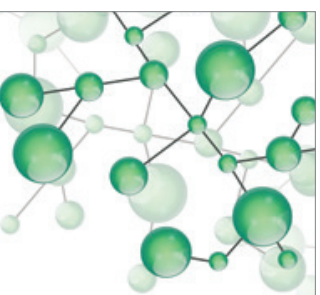

International Journal of

Inorganic Chemistry

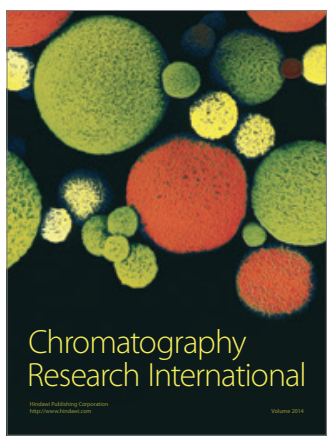

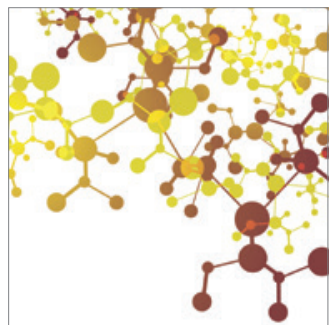

Applied Chemistry
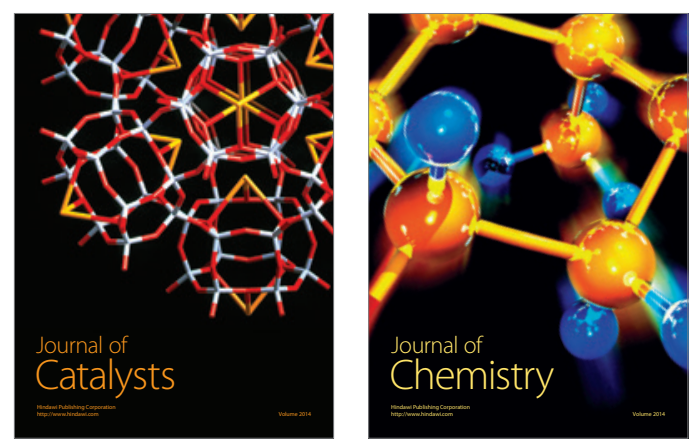
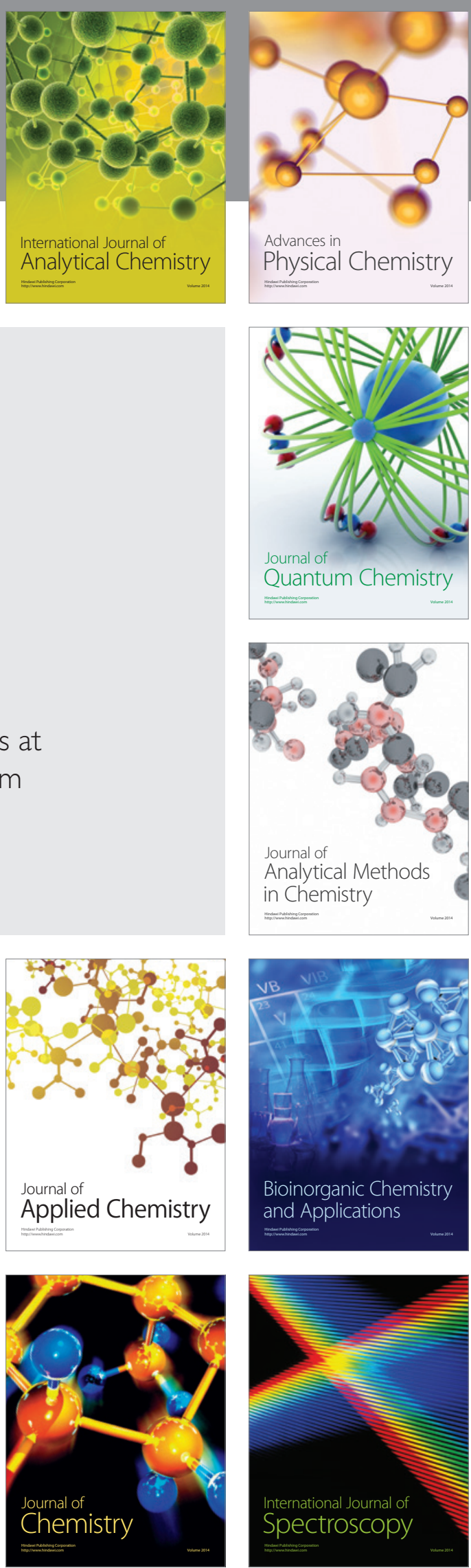